\title{
Isotopic Evolution of the Inner Solar System Inferred from Molybdenum Isotopes in Meteorites
}

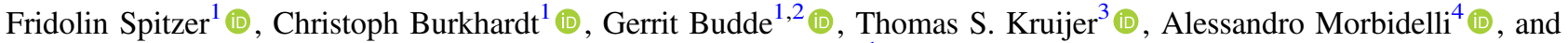 \\ Thorsten Kleine ${ }^{1}$ (iD \\ ${ }^{1}$ Institut für Planetologie, University of Münster, Wilhelm-Klemm-Str. 10, D-48149 Münster, Germany; fridolin.spitzer@uni-muenster.de \\ 2 The Isotoparium, Division of Geological and Planetary Sciences, California Institute of Technology, 1200 East California Boulevard, Pasadena, CA 91125, USA \\ ${ }^{3}$ Nuclear \& Chemical Sciences Division, Lawrence Livermore National Laboratory, 7000 East Avenue (L-231), Livermore, CA 94550, USA \\ ${ }^{4}$ Laboratoire Lagrange, UMR7293, Université de Nice Sophia-Antipolis, CNRS, Observatoire de la Cote d'Azur, Boulevard de l'Observatoire, F-06304 Nice Cedex \\ 4, France \\ Received 2020 March 27; revised 2020 June 17; accepted 2020 June 17; published 2020 July 16
}

\begin{abstract}
The fundamentally different isotopic compositions of non-carbonaceous (NC) and carbonaceous (CC) meteorites reveal the presence of two distinct reservoirs in the solar protoplanetary disk that were likely separated by Jupiter. However, the extent of material exchange between these reservoirs, and how this affected the composition of the inner disk, are not known. Here we show that $\mathrm{NC}$ meteorites display broadly correlated isotopic variations for $\mathrm{Mo}, \mathrm{Ti}, \mathrm{Cr}$, and $\mathrm{Ni}$, indicating the addition of isotopically distinct material to the inner disk. The added material resembles bulk CC meteorites and $\mathrm{Ca}-\mathrm{Al}$-rich inclusions in terms of its enrichment in neutron-rich isotopes, but unlike the latter materials is also enriched in $s$-process nuclides. The comparison of the isotopic composition of NC meteorites with the accretion ages of their parent bodies reveals that the isotopic variations within the inner disk do not reflect a continuous compositional change through the addition of CC dust, indicating an efficient separation of the $\mathrm{NC}$ and $\mathrm{CC}$ reservoirs and limited exchange of material between the inner and outer disk. Instead, the isotopic variations among NC meteorites more likely record a rapidly changing composition of the disk during infall from the Sun's parental molecular cloud, where each planetesimal locks the instant composition of the disk when it forms. A corollary of this model is that late-formed planetesimals in the inner disk predominantly accreted from secondary dust that was produced by collisions among pre-existing NC planetesimals.
\end{abstract}

Unified Astronomy Thesaurus concepts: Protoplanetary disks (1300); Planetesimals (1259); Nucleosynthesis (1131); R-process (1324); S-process (1419); Carbonaceous chondrites (200); Meteorites (1038); Meteorite composition (1037); Isotopic abundances (867); Accretion (14)

\section{Introduction}

Nucleosynthetic isotope anomalies reveal a fundamental dichotomy between non-carbonaceous (NC) and carbonaceous (CC) meteorites (Warren 2011; Budde et al. 2016), which sample two spatially distinct reservoirs that coexisted in the early solar system for several million years (Ma; Kruijer et al. 2017). The prolonged spatial separation of the $\mathrm{NC}$ and $\mathrm{CC}$ reservoirs most likely reflects the formation of Jupiter, which acted as an efficient barrier against material exchange either by its growth itself (Morbidelli et al. 2016; Kruijer et al. 2017) or through a pressure maximum in the disk near the location where Jupiter later formed (Brasser \& Mojzsis 2020). Although there is little doubt that the $\mathrm{NC}$ and CC reservoirs were spatially separated, the extent of material exchange between them remains poorly constrained. For example, the Jupiter barrier may have resulted in a filtering effect by which the inward drift of large grains was efficiently blocked, while smaller dust grains may have passed the barrier as part of the gas flow (Weber et al. 2018; Haugbølle et al. 2019). On this basis, it has been argued that the inner disk's isotopic composition was modified through the addition of inward-drifting CC dust (Schiller et al. 2018, 2020). This interpretation, however, depends on the assumed starting composition of the inner disk, and on the unknown efficiency of the Jupiter barrier over time. Thus, understanding and quantifying any compositional evolution of the NC reservoir is of considerable interest, as it would allow reconstructing the structure and temporal evolution of the solar accretion disk, and the importance of Jupiter for separating the NC and $\mathrm{CC}$ reservoirs.
The NC-CC dichotomy has been identified for several elements and so far holds for all analyzed meteorites (Kleine et al. 2020; Kruijer et al. 2020). The dichotomy is particularly exploitable for Mo, which can distinguish between isotope variations arising from the heterogeneous distribution of matter produced by the $p-, s-$, and $r$-processes of stellar nucleosynthesis (Burkhardt et al. 2011). While there are large s-process Mo isotope variations among meteorites within both the $\mathrm{NC}$ and $\mathrm{CC}$ groups, all CC meteorites are characterized by an approximately constant $r$-process excess over NC meteorites (Budde et al. 2016; Kruijer et al. 2017; Poole et al. 2017; Worsham et al. 2017). This difference makes Mo isotopes ideally suited to identify any compositional change of the $\mathrm{NC}$ reservoir, because the continuous addition of $\mathrm{CC}$ dust to the $\mathrm{NC}$ reservoir would result in a characteristic isotopic shift of the NC composition toward an enrichment in $r$-process Mo isotopes over time. For identifying such a potential isotopic shift in the NC reservoir, iron meteorites are particularly important, because they derive from some of the earliest planetesimals formed within the NC reservoir (Kruijer et al. 2014) and, therefore, may have a distinctly different Mo isotopic composition compared to later-formed $\mathrm{NC}$ planetesimals.

Until now, no systematic Mo isotopic difference between earlyand late-formed NC bodies has been identified (Budde et al. 2019). This might be due in part to the overall small Mo isotopic offset between the $\mathrm{NC}$ and $\mathrm{CC}$ reservoirs, but for iron meteorites it may also reflect the modification of their Mo isotopic compositions by neutron capture reactions induced during cosmic-ray exposure (CRE; e.g., Worsham et al. 2017). Here, we employ Pt isotopes to quantify CRE effects (Kruijer et al. 2013; Wittig et al. 2013) on 
Mo isotopes with unprecedented precision and use these data, combined with published data for other meteorite groups, to assess any compositional heterogeneity within the inner disk that may have arisen through material exchange between the $\mathrm{NC}$ and $\mathrm{CC}$ reservoirs.

\section{Molybdenum Isotopic Heterogeneity of the Inner Disk}

\subsection{Correction of CRE Effects}

Several group IC, IIAB, IID, and IIIAB irons with variable CRE effects on Pt isotopes were selected for this study. Except for the IID irons, only NC iron meteorites were selected, because this study aims to assess potential isotopic changes in inner disk composition. The IID irons were incorporated because one of them (Carbo) is among the most strongly irradiated irons known (Kruijer et al. 2013; Qin et al. 2015). Combined, the investigated samples include strongly and weakly irradiated irons, which makes it possible to precisely quantify CRE effects on Mo isotopes.

Sample preparation and Mo and Pt isotope measurements followed previously established methods (Kruijer et al. 2013; Budde et al. 2019). Isotopic compositions were determined using a Thermo-Fisher Neptune Plus MC-ICP-MS at Münster and are reported in the $\varepsilon$-notation (parts per 10,000 deviations from terrestrial standard values) after mass bias correction to the terrestrial ${ }^{98} \mathrm{Mo} /{ }^{96} \mathrm{Mo}$ and ${ }^{198} \mathrm{Pt} /{ }^{195} \mathrm{Pt}$, respectively.

Samples of a given iron group show variable $\varepsilon^{\mathrm{i}}$ Mo values that correlate with $\varepsilon^{196} \mathrm{Pt}$, indicating the presence of CRE effects (Figure 1). The $\varepsilon^{\mathrm{i}} \mathrm{Mo}-\varepsilon^{196} \mathrm{Pt}$ correlations are best defined for the IIAB and IID irons, both of which include samples with large CRE effects. Nevertheless, the IC and IIIAB irons also display correlated $\varepsilon^{\mathrm{i}} \mathrm{Mo}-\varepsilon^{196} \mathrm{Pt}$ variations, and the $\varepsilon^{\mathrm{i}} \mathrm{Mo}-\varepsilon^{196} \mathrm{Pt}$ slopes are consistent for all groups. The pre-exposure $\varepsilon^{i}$ Mo (i.e., unaffected by CRE) for each iron group can either be obtained from the intercept value at $\varepsilon^{196} \mathrm{Pt}=0$, or by individually correcting each sample to $\varepsilon^{196} \mathrm{Pt}=0$ and using the mean $\varepsilon^{\mathrm{i}} \mathrm{Mo}-\varepsilon^{196} \mathrm{Pt}$ slopes determined for the different iron groups. Both approaches yield identical results (Table 1) and provide precise pre-exposure $\varepsilon^{i} \mathrm{Mo}$ values for the IC, IIAB, IID, and IIIAB irons. Pre-exposure $\varepsilon^{i} \mathrm{Mo}$ values for the IIIE irons were calculated using previously published Mo and Pt isotopic data (Kruijer et al. 2017; Worsham et al. 2019; Table 1). The pre-exposure $\varepsilon^{i}$ Mo values of this study are a factor of $\sim 5$ more precise than previous results (Bermingham et al. 2018), and only for IIAB irons have values with comparable precision been previously reported (Yokoyama et al. 2019; Table 1). Finally, pre-exposure $\varepsilon^{\mathrm{i}}$ Mo values for IVA irons were calculated by averaging data for samples having no CRE effects (Poole et al. 2017) and CRE-corrected data (Bermingham et al. 2018).

\subsection{Mo Isotope Variations among NC Meteorites}

In a diagram of $\varepsilon^{95} \mathrm{Mo}$ versus $\varepsilon^{94} \mathrm{Mo}$, bulk meteorites plot along two distinct and approximately parallel lines, which were termed the NC and CC lines (Budde et al. 2016). The Mo isotopic variations along the $\mathrm{NC}$ and $\mathrm{CC}$ lines are predominantly governed by $s$-process variations, whereas the offset between the two lines reflects the characteristic $r$-process excess of the $\mathrm{CC}$ over the $\mathrm{NC}$ reservoir. For distinguishing between these different Mo isotope variations, it is useful to define $\Delta^{95} \mathrm{Mo}$ as the vertical deviation (in ppm) of a sample from an $s$-process mixing line passing through
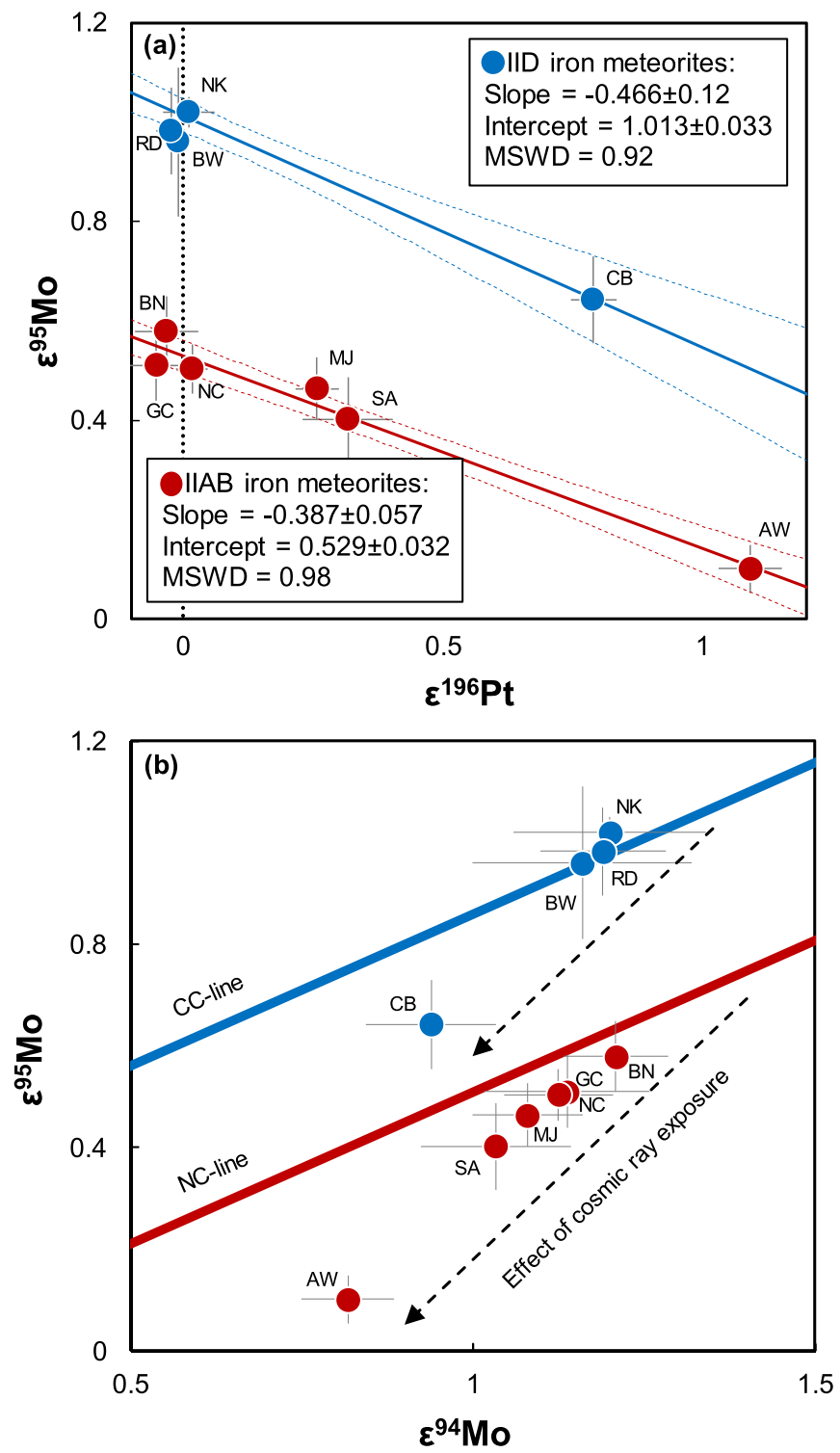

Figure 1. (a) $\varepsilon^{95}$ Mo vs. $\varepsilon^{196} \mathrm{Pt}$ for IIAB and IID iron meteorites. Both iron groups define precise and parallel correlation lines. Similar correlations are obtained for the other Mo isotopes as well as for the IC and IIIAB iron meteorites. The CRE effects on $\varepsilon^{196} \mathrm{Pt}$ are predominantly governed by the reaction ${ }^{195} \mathrm{Pt}(n, \gamma){ }^{196} \mathrm{Pt}$ and the comparably large neutron capture cross section and resonance integral for ${ }^{195} \mathrm{Pt}$ (Mughabghab 2003). For Mo isotopes the most important neutron capture reaction is ${ }^{95} \mathrm{Mo}(n, \gamma){ }^{96} \mathrm{Mo}$, and because ${ }^{96} \mathrm{Mo}$ is used as normalizing isotope, any CRE effect on ${ }^{96}$ Mo is transposed into all $\varepsilon^{i}$ Mo values. (b) $\varepsilon^{95}$ Mo vs. $\varepsilon^{94}$ Mo for IIAB and IID irons, showing that unaccounted CRE effects can result in significant departure from the NC and CC lines as defined in Budde et al. (2019). AW: Ainsworth; BN: Braunau; BW: Bridgewater; CB: Carbo; GC: Guadalupe y Calvo; MJ: Mount Joy; NC: North Chile; NK: N'kandhla; RD: Rodeo; SA: Sikhote Alin.

the origin (Budde et al. 2019):

$$
\Delta^{95} \mathrm{Mo}=\left(\varepsilon^{95} \mathrm{Mo}-0.596 \times \varepsilon^{94} \mathrm{Mo}\right) \times 100 .
$$

The quantity 0.596 is the slope of $s$-process mixing lines defined by bulk samples and acid leachates from both $\mathrm{NC}$ and $\mathrm{CC}$ meteorites (Budde et al. 2019), which is indistinguishable from the slope obtained from mainstream presolar $\mathrm{SiC}$ grains (Stephan et al. 2019). Distinct $\Delta^{95}$ Mo values, therefore, indicate Mo isotope heterogeneities unrelated to pure $s$-process variations.

The precise pre-exposure $\varepsilon^{95} \mathrm{Mo}$ and $\varepsilon^{94} \mathrm{Mo}$ values from this study reveal that some NC irons plot below the NC line (Figure 2), 
Table 1

Mo and Pt Isotope Data for IC, IIAB, IID, IIIAB, and IIIE Iron Meteorite Groups

\begin{tabular}{|c|c|c|c|c|c|c|c|c|c|c|c|c|}
\hline Sample & $\begin{array}{c}N^{\mathrm{a}} \\
\text { (Mo-IC) }\end{array}$ & $\begin{array}{c}N^{\mathrm{a}} \\
(\mathrm{Pt}-\mathrm{IC})\end{array}$ & $\begin{array}{l}\varepsilon^{92} \mathrm{Mo}_{\text {meas. }} \\
( \pm 95 \% \mathrm{CI})\end{array}$ & $\begin{array}{l}\varepsilon^{94} \mathrm{Mo}_{\text {meas }} \\
( \pm 95 \% \mathrm{CI})\end{array}$ & $\begin{array}{l}\varepsilon^{95} \mathrm{Mo}_{\text {meas. }} \\
( \pm 95 \% \mathrm{CI})\end{array}$ & $\begin{array}{l}\varepsilon^{97} \mathrm{Mo}_{\text {meas. }} \\
( \pm 95 \% \mathrm{CI})\end{array}$ & $\begin{array}{l}\varepsilon^{100} \mathrm{Mo}_{\text {meas. }} \\
( \pm 95 \% \mathrm{CI})\end{array}$ & $\begin{array}{c}\Delta^{95} \mathrm{Mo} \\
( \pm 95 \% \mathrm{CI})\end{array}$ & $\begin{array}{c}\varepsilon^{192} \mathrm{Pt} \\
( \pm 95 \% \mathrm{CI})\end{array}$ & $\begin{array}{c}\varepsilon^{194} \mathrm{Pt} \\
( \pm 95 \% \mathrm{CI})\end{array}$ & $\begin{array}{c}\varepsilon^{196} \mathrm{Pt} \\
( \pm 95 \% \mathrm{CI})\end{array}$ & References \\
\hline \multicolumn{13}{|l|}{ IC iron meteorites } \\
\hline Chihuahua City & 6 & 1 & $0.92 \pm 0.08$ & $0.88 \pm 0.06$ & $0.41 \pm 0.04$ & $0.25 \pm 0.06$ & $0.21 \pm 0.06$ & & $0.06 \pm 1.14$ & $0.21 \pm 0.15$ & $0.09 \pm 0.07$ & This study \\
\hline Mt. Dooling & 6 & 5 & $1.00 \pm 0.13$ & $0.91 \pm 0.08$ & $0.39 \pm 0.04$ & $0.25 \pm 0.03$ & $0.18 \pm 0.05$ & & $0.10 \pm 0.47$ & $-0.01 \pm 0.04$ & $-0.01 \pm 0.04$ & This study \\
\hline Arispe & 5 & 3 & $0.77 \pm 0.20$ & $0.75 \pm 0.14$ & $0.21 \pm 0.10$ & $0.14 \pm 0.07$ & $0.27 \pm 0.07$ & & $13.69 \pm 1.30$ & $0.67 \pm 0.11$ & $0.42 \pm 0.07$ & 1,2 \\
\hline Bendego & 5 & 7 & $0.83 \pm 0.07$ & $0.83 \pm 0.13$ & $0.26 \pm 0.06$ & $0.23 \pm 0.11$ & $0.31 \pm 0.18$ & & $0.79 \pm 0.78$ & $0.36 \pm 0.05$ & $0.48 \pm 0.05$ & 1,2 \\
\hline IC (int.-der.) ${ }^{\mathrm{b}}$ & & & $\mathbf{0 . 9 6} \pm \mathbf{0 . 0 8}$ & $0.90 \pm 0.06$ & $\mathbf{0 . 4 0} \pm \mathbf{0 . 0 3}$ & $\mathbf{0 . 2 5} \pm \mathbf{0 . 0 3}$ & $0.19 \pm 0.04$ & $-14 \pm 5$ & & & & \\
\hline IC (indiv.-corr.) ${ }^{\mathrm{c}}$ & & & $0.99 \pm 0.07$ & $0.92 \pm 0.06$ & $0.41 \pm 0.06$ & $0.24 \pm 0.07$ & $0.21 \pm 0.05$ & $-14 \pm 7$ & & & & \\
\hline \multicolumn{13}{|l|}{ IIAB iron meteorites } \\
\hline Ainsworth & 8 & 1 & $0.80 \pm 0.07$ & $0.82 \pm 0.07$ & $0.10 \pm 0.05$ & $0.23 \pm 0.05$ & $0.45 \pm 0.07$ & & $0.80 \pm 1.14$ & $0.57 \pm 0.15$ & $1.09 \pm 0.06$ & This study \\
\hline Braunau & 7 & 5 & $1.40 \pm 0.11$ & $1.21 \pm 0.08$ & $0.58 \pm 0.07$ & $0.34 \pm 0.08$ & $0.29 \pm 0.09$ & & $0.28 \pm 0.75$ & $-0.01 \pm 0.05$ & $-0.03 \pm 0.06$ & This study \\
\hline Guadalupe y Calvo & 5 & 5 & $1.27 \pm 0.27$ & $1.14 \pm 0.12$ & $0.51 \pm 0.07$ & $0.33 \pm 0.08$ & $0.32 \pm 0.14$ & & $0.36 \pm 0.75$ & $-0.05 \pm 0.05$ & $-0.05 \pm 0.06$ & This study \\
\hline Mount Joy & 7 & 5 & $1.27 \pm 0.06$ & $1.08 \pm 0.08$ & $0.46 \pm 0.06$ & $0.28 \pm 0.05$ & $0.37 \pm 0.05$ & & $0.25 \pm 0.57$ & $0.18 \pm 0.05$ & $0.26 \pm 0.04$ & This study \\
\hline North Chile & 5 & 5 & $1.29 \pm 0.13$ & $1.13 \pm 0.08$ & $0.50 \pm 0.05$ & $0.28 \pm 0.06$ & $0.34 \pm 0.13$ & & $0.03 \pm 1.53$ & $0.02 \pm 0.04$ & $0.02 \pm 0.03$ & This study \\
\hline Sikhote Alin & 7 & 1 & $1.12 \pm 0.16$ & $1.03 \pm 0.11$ & $0.40 \pm 0.08$ & $0.24 \pm 0.08$ & $0.39 \pm 0.09$ & & $0.67 \pm 1.14$ & $0.32 \pm 0.11$ & $0.32 \pm 0.09$ & This study \\
\hline IIAB (int.-der.) ${ }^{\mathrm{b}}$ & & & $1.37 \pm \mathbf{0 . 0 6}$ & $1.16 \pm 0.04$ & $\mathbf{0 . 5 3} \pm \mathbf{0 . 0 3}$ & $\mathbf{0 . 3 0} \pm \mathbf{0 . 0 3}$ & $\mathbf{0 . 3 3} \pm \mathbf{0 . 0 5}$ & $-16 \pm 4$ & & & & \\
\hline IIAB (indiv.-corr.) ${ }^{\mathrm{c}}$ & & & $1.32 \pm 0.06$ & $1.15 \pm 0.03$ & $0.53 \pm 0.03$ & $0.31 \pm 0.03$ & $0.33 \pm 0.02$ & $-15 \pm 4$ & & & & \\
\hline \multicolumn{13}{|l|}{ IID iron meteorites } \\
\hline Carbo & 8 & 7 & $1.28 \pm 0.12$ & $0.94 \pm 0.10$ & $0.64 \pm 0.09$ & $0.42 \pm 0.04$ & $0.68 \pm 0.08$ & & $33.57 \pm 0.40$ & $1.27 \pm 0.07$ & $0.79 \pm 0.04$ & This study \\
\hline Rodeo & 6 & 5 & $1.63 \pm 0.16$ & $1.19 \pm 0.09$ & $0.98 \pm 0.09$ & $0.51 \pm 0.03$ & $0.52 \pm 0.12$ & & $-0.01 \pm 0.65$ & $-0.01 \pm 0.08$ & $-0.02 \pm 0.03$ & This study \\
\hline Bridgewater & 7 & 5 & $1.63 \pm 0.10$ & $1.16 \pm 0.16$ & $0.96 \pm 0.15$ & $0.51 \pm 0.12$ & $0.67 \pm 0.17$ & & $0.80 \pm 0.90$ & $0.02 \pm 0.08$ & $-0.01 \pm 0.02$ & 1,2 \\
\hline N'kandhla & 5 & 5 & $1.71 \pm 0.15$ & $1.20 \pm 0.14$ & $1.02 \pm 0.03$ & $0.50 \pm 0.03$ & $0.59 \pm 0.07$ & & $0.64 \pm 0.23$ & $0.03 \pm 0.05$ & $0.01 \pm 0.05$ & 1,2 \\
\hline IID (int.-der.) ${ }^{\mathrm{b}}$ & & & $\mathbf{1 . 6 5} \pm \mathbf{0 . 0 7}$ & $\mathbf{1 . 1 8} \pm \mathbf{0 . 0 7}$ & $1.01 \pm \mathbf{0 . 0 3}$ & $0.50 \pm \mathbf{0 . 0 2}$ & $0.58 \pm 0.06$ & $\mathbf{3 1} \pm \mathbf{5}$ & & & & \\
\hline IID (indiv.-corr.) ${ }^{\mathrm{c}}$ & & & $1.66 \pm 0.06$ & $1.18 \pm 0.03$ & $0.98 \pm 0.06$ & $0.50 \pm 0.02$ & $0.59 \pm 0.10$ & $27 \pm 6$ & & & & \\
\hline \multicolumn{13}{|l|}{ IIIAB iron meteorites } \\
\hline Boxhole & 9 & 9 & $0.98 \pm 0.05$ & $0.89 \pm 0.06$ & $0.35 \pm 0.02$ & $0.27 \pm 0.04$ & $0.30 \pm 0.05$ & & $23.16 \pm 0.53$ & $0.77 \pm 0.04$ & $0.41 \pm 0.01$ & This study \\
\hline Cape York & 8 & 5 & $1.09 \pm 0.12$ & $1.01 \pm 0.06$ & $0.47 \pm 0.07$ & $0.23 \pm 0.05$ & $0.26 \pm 0.09$ & & $-0.19 \pm 0.57$ & $0.05 \pm 0.04$ & $0.01 \pm 0.04$ & This study \\
\hline Costilla Peak & 7 & 7 & $1.13 \pm 0.14$ & $1.03 \pm 0.10$ & $0.48 \pm 0.09$ & $0.27 \pm 0.05$ & $0.25 \pm 0.10$ & & $-0.14 \pm 0.73$ & $-0.02 \pm 0.03$ & $-0.04 \pm 0.03$ & This study \\
\hline Henbury & 7 & 8 & $1.05 \pm 0.19$ & $0.97 \pm 0.10$ & $0.42 \pm 0.05$ & $0.26 \pm 0.02$ & $0.17 \pm 0.14$ & & $15.58 \pm 0.50$ & $0.48 \pm 0.04$ & $0.26 \pm 0.04$ & This study \\
\hline Willamette & 7 & 7 & $1.07 \pm 0.16$ & $0.92 \pm 0.13$ & $0.43 \pm 0.07$ & $0.25 \pm 0.10$ & $0.20 \pm 0.08$ & & $-0.38 \pm 0.66$ & $-0.02 \pm 0.06$ & $-0.05 \pm 0.04$ & This study \\
\hline Youanmi & 7 & 4 & $1.12 \pm 0.05$ & $1.02 \pm 0.07$ & $0.39 \pm 0.06$ & $0.25 \pm 0.07$ & $0.22 \pm 0.06$ & & $4.39 \pm 0.48$ & $0.45 \pm 0.02$ & $0.29 \pm 0.09$ & This study \\
\hline IIIAB (int.-der.) ${ }^{\mathrm{b}}$ & & & $\mathbf{1 . 1 5} \pm \mathbf{0 . 0 7}$ & $1.01 \pm \mathbf{0 . 0 4}$ & $0.46 \pm 0.04$ & $\mathbf{0 . 2 6} \pm \mathbf{0 . 0 3}$ & $0.22 \pm \mathbf{0 . 0 5}$ & $-15 \pm 5$ & & & & \\
\hline IIIAB (indiv.-corr.) ${ }^{\mathrm{c}}$ & & & $1.15 \pm 0.07$ & $1.02 \pm 0.06$ & $0.48 \pm 0.03$ & $0.27 \pm 0.03$ & $0.21 \pm 0.05$ & $-13 \pm 5$ & & & & \\
\hline $\begin{array}{l}\text { IIIE iron meteorites } \\
\text { (indiv.-corr.) }^{\mathrm{c}}\end{array}$ & & & $1.08 \pm 0.06$ & $0.96 \pm 0.02$ & $0.46 \pm 0.06$ & $0.30 \pm 0.04$ & $0.27 \pm 0.09$ & $-11 \pm 6$ & & & & 1,2 \\
\hline
\end{tabular}

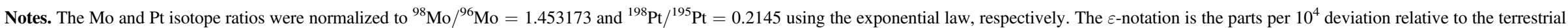

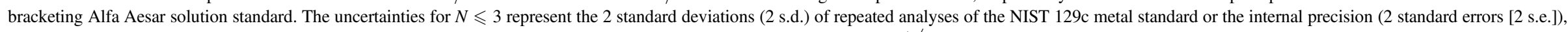
whichever is larger. The uncertainties for $N \geqslant 4$ represent the Student- $t 95 \%$ confidence intervals, i.e., $\left(t_{0.95}, N-1 \times\right.$ s.d. $) / \sqrt{ } N$. The bold values represent the CRE-corrected group averages.

${ }^{a}$ Number of measurements.

${ }^{\mathrm{b}}$ Intercept-derived values at $\varepsilon^{196} \mathrm{Pt}=0$ from $\varepsilon^{\mathrm{i}} \mathrm{Mo}-\varepsilon^{196} \mathrm{Pt}$ correlations for each group.

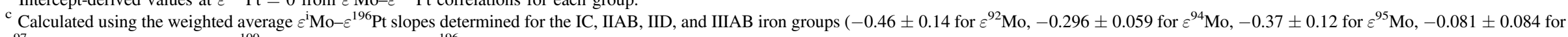
$\varepsilon^{97} \mathrm{Mo}$, and $0.130 \pm 0.058$ for $\varepsilon^{100} \mathrm{Mo}$ ) and the measured $\varepsilon^{196} \mathrm{Pt}$.

References. (1) Worsham et al. (2019), (2) Kruijer et al. (2017). 

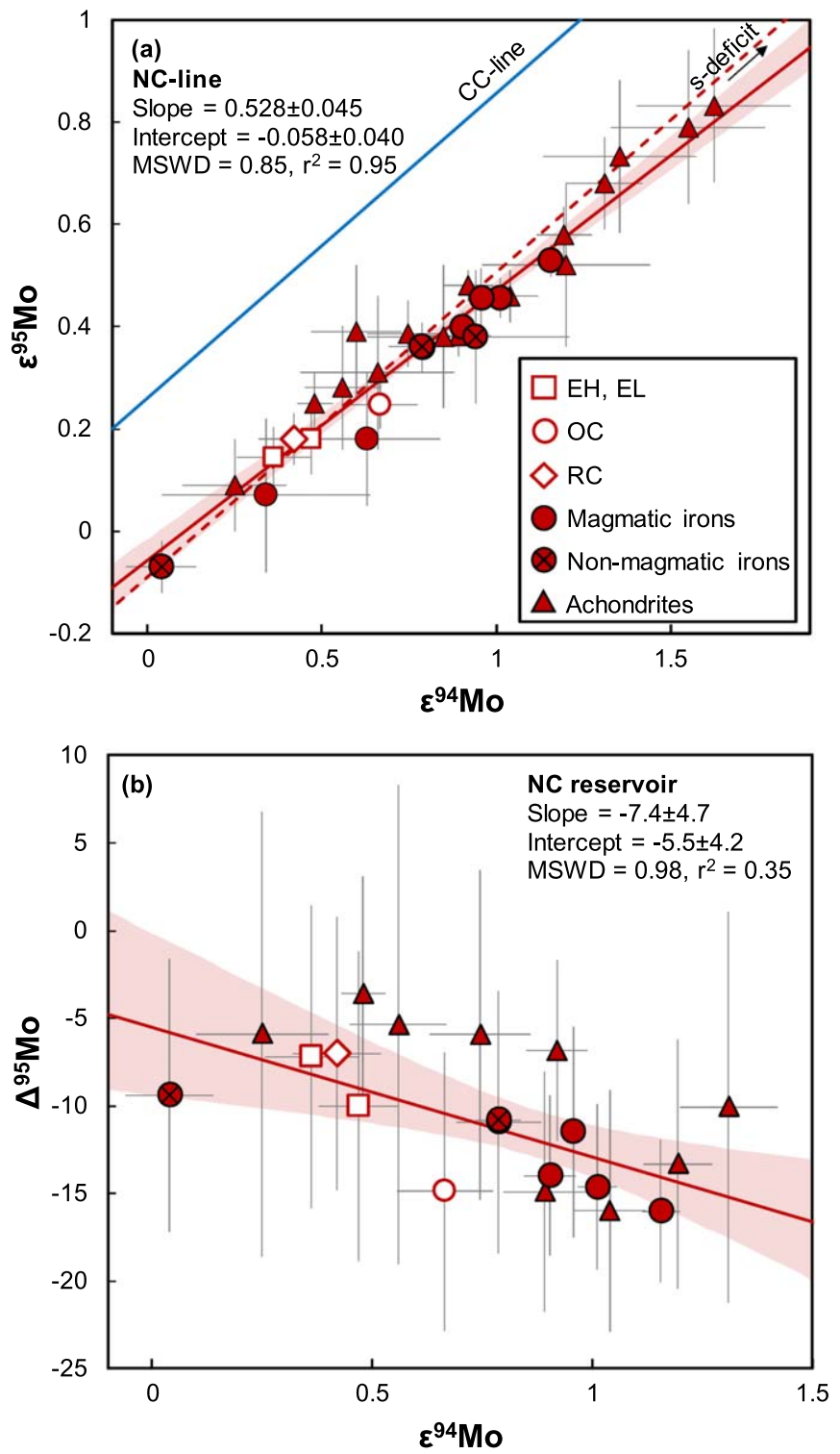

Figure 2. $\varepsilon^{95}$ Mo vs. $\varepsilon^{94}$ Mo (a) and $\Delta^{95}$ Mo vs. $\varepsilon^{94}$ Mo (b) for NC meteorites. CC line (blue) and NC line (dashed red line) as defined in Budde et al. (2019) shown for reference. All regressions were calculated using the model 1 fit of Isoplot (Ludwig 2008). (a) Note that some iron meteorites plot below the previously defined NC line and that NC meteorites plot along a line with a slightly shallower slope compared to the $\mathrm{CC}$ line. (b) $\mathrm{NC}$ meteorites define a weak inverse correlation of $\Delta^{95}$ Mo vs. $\varepsilon^{94}$ Mo (only includes samples having $\Delta^{95}$ Mo uncertainties $<15$ ppm). Correlated uncertainties for $\Delta^{95}$ Mo and $\varepsilon^{94}$ Mo were taken into account in the regression, but error ellipses are omitted for clarity.

and have slightly lower $\Delta^{95}$ Mo than the characteristic NC value $\left(\Delta^{95} \mathrm{Mo}=-9 \pm 2\right.$; Budde et al. 2019; Table 1). Linear regression of available $\varepsilon^{95} \mathrm{Mo}$ and $\varepsilon^{94} \mathrm{Mo}$ data for $\mathrm{NC}$ meteorites (Table A1 in the Appendix), including the precise data for NC irons from this study, yields a slope of $0.528 \pm 0.045(\mathrm{MSWD}=0.85)$, which is shallower than the slope of the CC line and the characteristic slope of a pure $s$-process mixing line (Figure 2). Including leachate data for NC chondrites (Budde et al. 2019) results in a steeper slope ( $m=0.595 \pm 0.011$ ), which is consistent with that of the CC line and pure $s$-process variations. However, the higher MSWD of 1.6 for this regression is above the upper acceptable limit of 1.45 for $N$ $=41$ (Wendt \& Carl 1991), indicating additional scatter outside the analytical uncertainties. The $\varepsilon^{95} \mathrm{Mo}-\varepsilon^{94} \mathrm{Mo}$ slope of bulk NC meteorites, therefore, is shallower than the predicted slope of a pure $s$-process mixing line. This results in a weak inverse correlation of $\Delta^{95} \mathrm{Mo}$ with $\varepsilon^{94} \mathrm{Mo}$ (Figure 2) and indicates that the Mo isotope variations among NC meteorites do not solely reflect $s$-process but also additional $r$-process variations.

\section{Isotopic Evolution of the Inner Solar System}

\subsection{Mixing Trends in the NC Reservoir}

The $\Delta^{95}$ Mo and $\varepsilon^{94}$ Mo values of NC meteorites are not only correlated with another, but also with $\varepsilon^{50} \mathrm{Ti}, \varepsilon^{54} \mathrm{Cr}$, and $\varepsilon^{62} \mathrm{Ni}$ (Figure 3). These correlations involve lithophile ( $\mathrm{Ti}, \mathrm{Cr}$ ) and siderophile ( $\mathrm{Ni}, \mathrm{Mo}$ ) as well as refractory (Ti, Mo) and nonrefractory $(\mathrm{Cr}, \mathrm{Ni})$ elements, indicating that the isotopic variations do not reflect the heterogeneous distribution of individual presolar carriers (e.g., SiC) or chemically fractionated components (e.g., refractory inclusions, silicates, metal). Instead, they are indicative of mixing between two isotopically distinct components with similar bulk chemical compositions. One of the mixing endmembers has the characteristic isotopic composition of the NC reservoir (low $\Delta^{95} \mathrm{Mo}, \varepsilon^{50} \mathrm{Ti}, \varepsilon^{54} \mathrm{Cr}$, and $\varepsilon^{62} \mathrm{Ni}$ ), while the other has high $\Delta^{95} \mathrm{Mo}, \varepsilon^{50} \mathrm{Ti}, \varepsilon^{54} \mathrm{Cr}$, and $\varepsilon^{62} \mathrm{Ni}$ (Figures 3(a)-(c)), which are the isotopic characteristics of bulk CC meteorites and $\mathrm{Ca}-\mathrm{Al}$-rich inclusions (CAIs).

However, unlike for $\Delta^{95} \mathrm{Mo}$ (Figures 3(a)-(c)), NC meteorites, $\mathrm{CC}$ meteorites, and CAIs do not define a single mixing line in $\varepsilon^{94} \mathrm{Mo}$ versus $\varepsilon^{50} \mathrm{Ti}-\varepsilon^{54} \mathrm{Cr}-\varepsilon^{62} \mathrm{Ni}$ diagrams (Figures $3(\mathrm{~d})-(\mathrm{f})$ ). Instead, $\mathrm{NC}$ meteorites plot along a trend toward more positive $\varepsilon^{50} \mathrm{Ti}, \varepsilon^{54} \mathrm{Cr}$, and $\varepsilon^{62} \mathrm{Ni}$, but negative $\varepsilon^{94} \mathrm{Mo}$ (Figures 3(d)-(f)). By contrast, bulk CC meteorites and typical CAIs are characterized by positive $\varepsilon^{94} \mathrm{Mo}$ and, therefore, plot off this trend (Figures 3(d)(f)). This also includes CI chondrites, which have been suggested to represent the material that was added to the inner disk and continuously changed its composition (Schiller et al. 2020). Thus, although one of the endmembers defining the NC mixing trend has some isotopic characteristics of CC meteorites and CAIs, compared to these samples this material is characterized by negative $\varepsilon^{94} \mathrm{Mo}$, which is indicative of an excess in $s$-process Mo. The only known meteoritic materials with such a composition are the matrix of the CV3 chondrite Allende (Budde et al. 2016) and some fine-grained CAIs (Brennecka et al. 2017). We emphasize that this does not imply that these materials physically represent one of the endmembers defining the NC mixing trend, but it merely reveals that material with appropriate isotopic compositions existed in the disk at various times.

Like the NC mixing trend, the NC-CC dichotomy probably also results from mixing between two reservoirs with overall chondritic chemical but distinct isotopic compositions (Burkhardt et al. 2019; Nanne et al. 2019). In this model, the earliest disk, which formed by viscous spreading of early infalling material (Yang \& Ciesla 2012; Jacquet et al. 2019), was characterized by a CAI-like isotopic composition (inclusion-like chondritic reservoir (IC); Burkhardt et al. 2019), while the later infall had a NC-like isotopic composition and provided most of the material in the inner disk. Mixing within the disk then gave rise to the $\mathrm{CC}$ reservoir, whose isotopic composition is intermediate between those of the IC and NC reservoirs (Burkhardt et al. 2019; Nanne et al. 2019). Thus, similar mixing processes that produced the $\mathrm{NC}-\mathrm{CC}$ dichotomy also seem to be responsible for the isotopic variations within the $\mathrm{NC}$ reservoir, with the important difference that the material that produced the NC mixing trend is enriched in $s$-process Mo compared to the material that produced the $\mathrm{NC}-\mathrm{CC}$ dichotomy (Figure 3). Consequently, to account for both the 

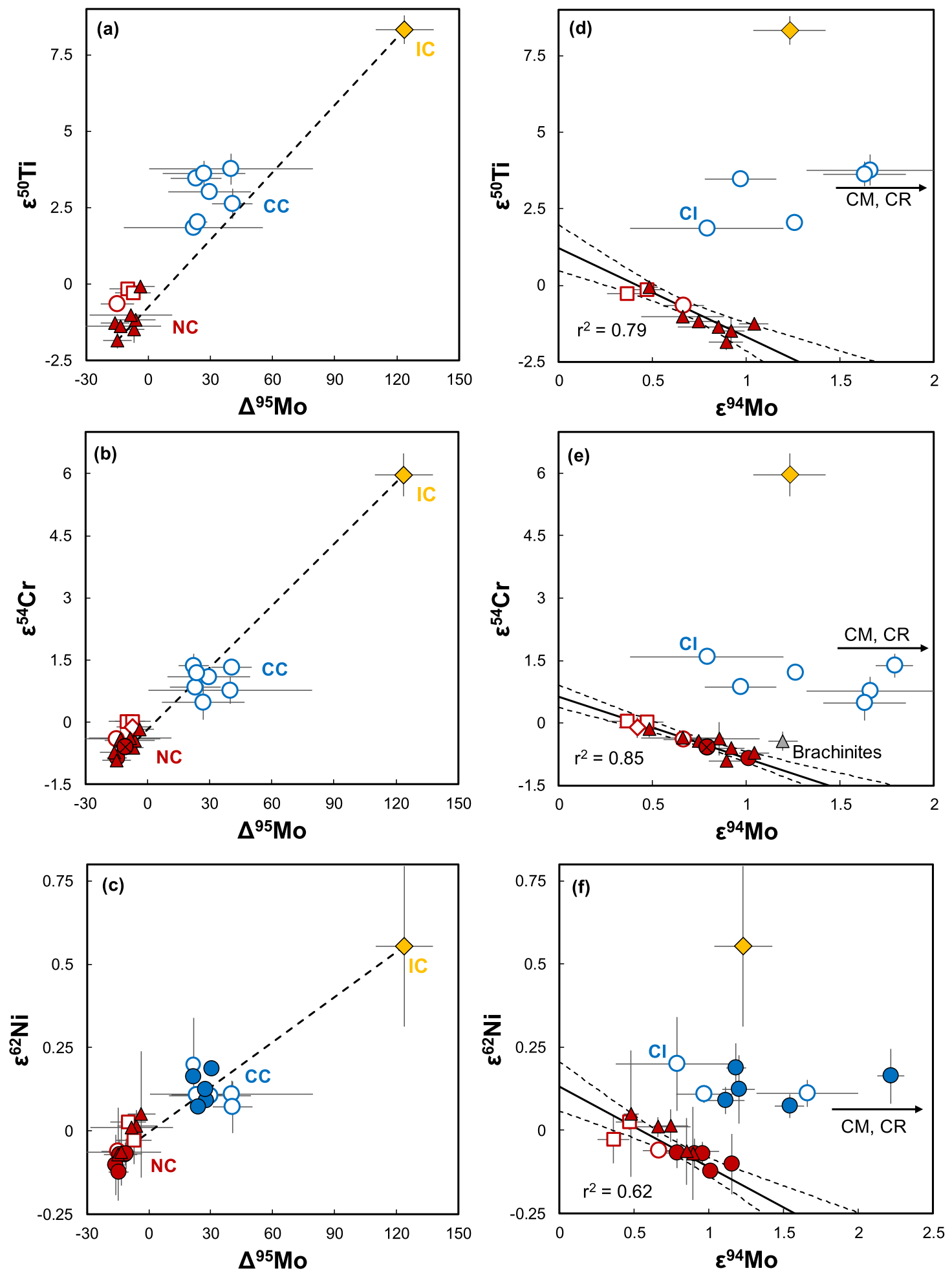

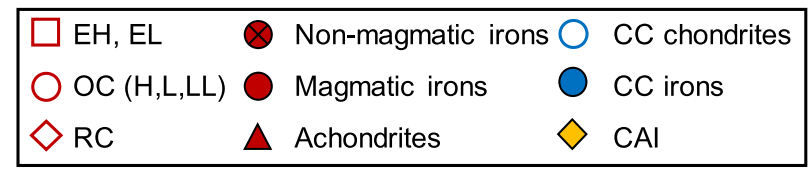

Figure 3. $\Delta^{95} \mathrm{Mo}$ and $\varepsilon^{94} \mathrm{Mo}$ vs. $\varepsilon^{50} \mathrm{Ti}, \varepsilon^{54} \mathrm{Cr}$, and $\varepsilon^{62} \mathrm{Ni}$ for $\mathrm{NC}$ meteorites, $\mathrm{CC}$ meteorites, and $\mathrm{CAI}$ (labeled "IC" for inclusion-like chondritic reservoir). For data sources see Table A1. (a)-(c) For $\Delta^{95} \mathrm{Mo} v \mathrm{vs} . \varepsilon^{50} \mathrm{Ti}-\varepsilon^{54} \mathrm{Cr}-\varepsilon^{62} \mathrm{Ni}$, the composition of all meteorites can be accounted for by mixing between an initial NC reservoir characterized by the lowest $\Delta^{95} \mathrm{Mo}-\varepsilon^{50} \mathrm{Ti}-\varepsilon^{54} \mathrm{Cr}-\varepsilon^{62} \mathrm{Ni}$ values and the IC reservoir, as indicated by the dashed black line. (d) -(f) For $\varepsilon^{94} \mathrm{Mo}$ vs. $\varepsilon^{50} \mathrm{Ti}-\varepsilon^{54} \mathrm{Cr}-\varepsilon^{62} \mathrm{Ni}$, only NC meteorites display correlated variations, but bulk CC meteorites and CAI plot off these trends toward more positive $\varepsilon^{94} \mathrm{Mo}$ (i.e., $s$-process depleted compositions). Note that CM and CR chondrites plot off scale toward larger $\varepsilon^{94} \mathrm{Mo}$. Solid black line is a linear regression through data for NC meteorites, calculated using Isoplot (Ludwig 2008). Dashed lines show the error envelope of the regression. Note that brachinites are excluded from the regression, because their isotopic composition might have been modified during partial differentiation (Hopp et al. 2020). 
isotopic variations in the $\mathrm{NC}$ reservoir and the $\mathrm{NC}-\mathrm{CC}$ dichotomy requires at least three components: (1) the characteristic starting composition of the NC reservoir (e.g., as given by magmatic irons); (2) $s$-process-depleted IC material (as observed for most CAIs); and (3) $s$-process-enriched IC or CC material. Mixing between the first two of these components (i.e., between $\mathrm{NC}$ and IC) resulted in the characteristic composition of the $\mathrm{CC}$ reservoir, whereas mixing between the first and the third component (i.e., between NC and s-enriched IC or CC) produced the isotopic variations within the $\mathrm{NC}$ reservoir.

\subsection{Spatial and Temporal Variations in the NC Reservoir}

The addition of $s$-process-enriched IC or CC material to the inner disk may have occurred by different processes and at different times. For instance, isotopic heterogeneities in the inner disk may be inherited from the molecular cloud and would then reflect the changing isotopic composition of infalling matter from IC to NC at a very early stage when the NC reservoir was still forming (Burkhardt et al. 2019; Jacquet et al. 2019; Nanne et al. 2019). Alternatively, the outward transport of isotopically anomalous refractory material (e.g., CAIs) through the inner disk may have led to isotopic heterogeneities, because the fraction of CAIs remaining in the inner disk is expected to be higher at early times (Desch et al. 2018). Finally, the isotopic composition of the inner disk may have changed over time through the addition of CC-like dust from the outer solar system after the $\mathrm{NC}-\mathrm{CC}$ dichotomy had been established (Schiller et al. 2018). We note, however, that the NC mixing trend points toward $s$-enriched IC or CC material, rather than to the $s$-depleted IC or CC compositions as sampled by typical CAIs and bulk CC meteorites, respectively (Figure 3). Thus, the NC mixing trend cannot result from the addition of these latter materials, but it may still reflect the addition of $s$-enriched IC or CC material. These additions would have likely resulted in distinct isotopic compositions for early- and late-accreted NC planetesimals, and so assessing whether the isotopic variations among $\mathrm{NC}$ meteorites are correlated with the accretion ages of their parent bodies may help to identify the underlying mechanisms that produced the NC mixing trend.

The accretion ages of NC iron meteorite and chondrite parent bodies are reasonably well established. For instance, ${ }^{182} \mathrm{Hf}-{ }^{182} \mathrm{~W}$ ages for most $\mathrm{NC}$ iron meteorites (i.e., group IC, IIAB, IIIAB, and IVA irons) indicate parent body accretion within $<0.5 \mathrm{Ma}$ after CAI formation (Kruijer et al. 2014, 2017). Only the IAB and IIE iron meteorite parent bodies may have accreted slightly later (Hunt et al. 2018; Kruijer \& Kleine 2019), but their younger Hf-W ages may also reflect resetting during impact events, in which case the original accretion age is unknown (Kruijer \& Kleine 2019). The parent bodies of $\mathrm{NC}$ chondrites accreted at $\sim 2 \mathrm{Ma}$ after CAI formation (Blackburn et al. 2017; Hellmann et al. 2019; Pape et al. 2019) and, therefore, later than those of the irons. Although accretion ages are only available for ordinary chondrites, it is reasonable to assume that the enstatite and Rumuruti chondrite parent bodies accreted at about the same time, given that all these bodies remained unmelted and, therefore, accreted later than $\sim 1.5$ Ma after CAI formation to avoid melting by ${ }^{26} \mathrm{Al}$ decay (Hevey \& Sanders 2006). Thus, when only iron meteorites and chondrites are considered, a temporal trend appears to exist in the isotopic composition of $\mathrm{NC}$ meteorites from lower to higher values of $\Delta^{95} \mathrm{Mo}, \varepsilon^{50} \mathrm{Ti}, \varepsilon^{54} \mathrm{Cr}$, and $\varepsilon^{62} \mathrm{Ni}$ (Figure 4). This trend is opposite to the expected isotopic variations for the incorporation of different amounts of refractory inclusions (e.g., CAIs) in NC planetesimals, which predicts more elevated $\Delta^{95} \mathrm{Mo}, \varepsilon^{50} \mathrm{Ti}, \varepsilon^{54} \mathrm{Cr}$, and $\varepsilon^{62} \mathrm{Ni}$ in
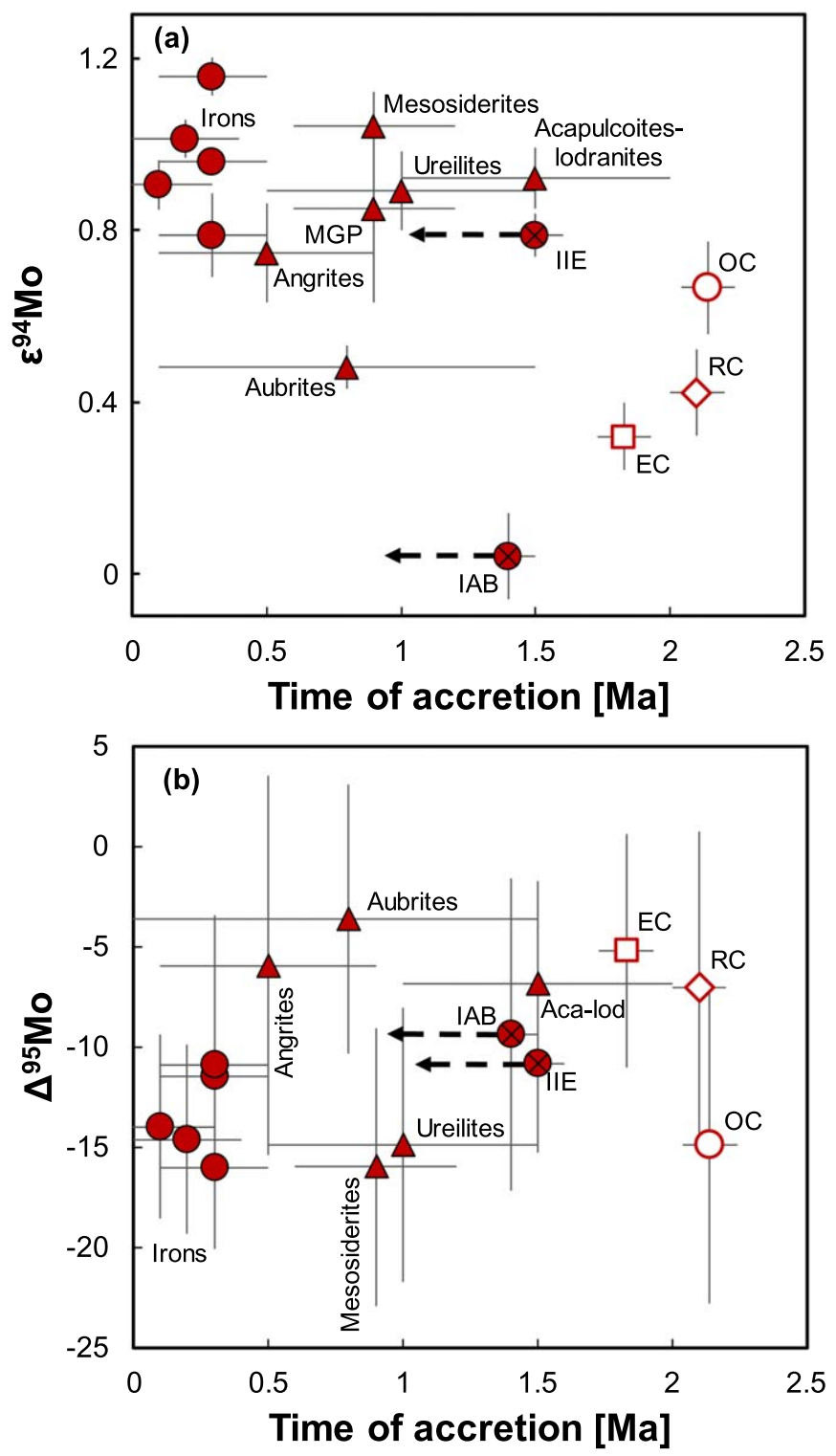

Figure 4. $\varepsilon^{94} \mathrm{Mo}$ (a) and $\Delta^{95} \mathrm{Mo}(\mathrm{b})$ vs. accretion ages for NC meteorites. Accretion ages are summarized in Table A1. Note that some anomalous ureilites display larger $\varepsilon^{94}$ Mo anomalies, but these samples are not shown here because their accretion ages are unknown (see Table A1). Arrows indicate that accretion ages may be older than shown. Legend as in Figure 3. MGP: Main Group Pallasites.

early-formed objects, reflecting the larger fraction of refractory inclusions in the inner disk at early times (Desch et al. 2018). Instead, the apparent temporal trend defined by iron meteorites and chondrites appears consistent with the expected effects of $\mathrm{CC}$ dust addition to the inner disk, which should have produced more $\mathrm{CC}$ like isotopic compositions in later-accreted NC bodies.

However, some other NC meteorites do not seem to fit the trend of isotope anomalies versus accretion ages very well. For instance, the ureilite parent body may have accreted as late as $1.5 \mathrm{Ma}$ after CAIs (Budde et al. 2015), yet seems to have the lowest contribution of CC material among all NC meteorites. Moreover, acapulcoiteslodranites, whose parent body likely accreted at $\sim 1.5 \mathrm{Ma}$ after CAIs (Touboul et al. 2009), are also characterized by lower $\Delta^{95} \mathrm{Mo}, \varepsilon^{50} \mathrm{Ti}$, and $\varepsilon^{54} \mathrm{Cr}$ values than, for instance, the angrites, whose parent body likely accreted within the first $\sim 0.5-1 \mathrm{Ma}$ of the solar system (Kleine et al. 2012; Hans et al. 2013). Finally, 
aubrites and enstatite chondrites have very similar isotopic compositions, but the aubrite parent body likely accreted earlier, well within $1.5 \mathrm{Ma}$ after CAI formation (Sugiura \& Fujiya 2014). Differentiated meteorites, therefore, appear to cover most of the isotopic range observed among NC meteorites, yet these meteorites probably derive from bodies that accreted rather early. Similarly, later-accreted NC planetesimals (e.g., parent bodies of acapulcoiteslodranites and enstatite, ordinary, and Rumuruti chondrites) appear to cover a similar range of isotopic anomalies (Figure 4). Together, these observations reveal that the $\mathrm{NC}$ isotopic mixing trend cannot solely reflect a temporal evolution of inner disk composition by addition of $s$-enriched CC dust from the outer solar system.

The lack of a clear temporal trend in the inner disk's isotopic composition suggests that the NC mixing trend at least partially reflects spatial variations. These are unlikely to result from mixing between NC and CC materials, because, as noted above, this would lead to a temporal trend in the isotope anomalies. Instead, spatial variations within the inner disk more likely result from mixing between $s$-enriched IC and NC material, which occurred during infall from the Sun's parental molecular cloud and the associated early stages of disk building. It has been shown theoretically that infall from an isotopically zoned molecular cloud may result not only in an isotopically distinct outer disk (i.e., the $\mathrm{CC}$ reservoir), but also in spatial isotopic heterogeneities within the inner disk (Jacquet et al. 2019). The NC mixing trend may, therefore, at least in part reflect mixing of $s$-enriched IC and NC materials during infall and the early stages of disk building.

\section{Implications for Planetesimal Formation in the Inner Disk}

As noted in prior studies, the clear compositional gap between the NC and CC reservoirs in multi-element isotope space (Figure 3) requires the efficient separation of both reservoirs by a physical barrier, which may either be Jupiter itself (Kruijer et al. 2017) or, more generally, a pressure maximum in the disk (Brasser \& Mojzsis 2020). This efficient separation implies that there has been only limited replenishment of dust in the inner disk through inward-drifting $\mathrm{CC}$ dust. Thus, the inner disk is expected to become rapidly depleted in dust through rapid accretion into planetesimals (e.g., NC iron parent bodies) and loss to the Sun. This raises the question of how there was sufficient dust available in the inner disk for the $\sim 2$ Ma period of planetesimal formation inferred from the chronology of NC meteorites. Moreover, as noted above, if the $\mathrm{NC}$ isotopic mixing trend reflects spatial heterogeneities within the inner disk, then these isotopic variations must also be preserved for the $\sim 2$ Ma period of $\mathrm{NC}$ planetesimal formation. Together, these observations imply either that dust in the inner disk was somehow stored for at least $\sim 2 \mathrm{Ma}$, or that laterformed $\mathrm{NC}$ planetesimals predominantly accreted from secondary dust produced by collisions among pre-existing planetesimals.

Pressure maxima in the inner disk are a potential way for storage of dust and would have also prevented mixing of dust across the resulting gap. However, a pressure bump would have also resulted in dust pile-up and, ultimately, its rapid accretion into planetesimals (e.g., Morbidelli et al. 2020). As such, it is unclear why some of these putative pressure maxima in the inner disk would have converted dust into planetesimals very rapidly (e.g., $\mathrm{NC}$ iron parent bodies), while others preserved dust for $\sim 2 \mathrm{Ma}$ until accretion into planetesimals (e.g., NC chondrite parent bodies). This would require different efficiencies with which pressure maxima resulted in the concentration of dust, but whether this is feasible is unknown. Thus, although we cannot exclude that pressure maxima in the inner disk resulted in a prolonged preservation of dust, the distinct accretion times of NC meteorite parent bodies make this scenario less likely.

By contrast, secondary dust would be produced naturally in the inner disk during the later stages of its evolution, when the damping effect of gas on the planetesimals' velocity dispersion becomes weaker and protoplanets become more massive so that they can scatter planetesimals more efficiently (Gerbig et al. 2019). Moreover, the lower amount of gas remaining at later stages favors planetesimal formation by the streaming instability, because the dust-to-gas ratio is high even for low amounts of dust (Carrera et al. 2017). Thus, from a dynamical standpoint the formation of planetesimals from secondary dust is expected, and so we consider it the more likely mechanism to account for the prolonged interval of planetesimal formation in the inner disk.

$\mathrm{NC}$ chondrites have broadly solar iron-to-metal ratios and overall chondritic relative abundances of non-volatile elements, indicating formation from chemically unfractionated dust (Palme et al. 2014). Thus, forming NC chondrites from collisionally produced dust requires that this dust predominantly derives from small planetesimals that were unable to chemically differentiate, or from the primitive crust of larger, differentiated objects (Elkins-Tanton et al. 2011). Alternatively, highly energetic collisions may have resulted in vaporization of the colliding planetesimals, as has been suggested in some recent models for chondrule formation in the inner solar system (Lock et al. 2019; Stewart et al. 2019). We note, however, that the formation of $\mathrm{NC}$ chondrites from collisionally produced dust does not necessarily imply that the chondrules themselves formed as a result of these collisions. It is also possible that the chondrule-melting events occurred later by another process, and were unrelated to the collisions that produced their precursor dust. Distinguishing between these different models is not possible using the data of this study, but will require a better understanding of the underlying mechanisms that produced chondrules and whether or not this process was different in the inner and outer solar system.

Finally, the formation of NC chondrites from secondary dust implies that their isotopic composition does not provide a snapshot of inner disk composition at the time of parent body accretion at $\sim 2 \mathrm{Ma}$, but instead reflects those of pre-existing planetesimals and, therefore, records an earlier time of disk evolution. As such, there is no need to preserve spatial isotopic variations within the NC reservoir for a period of $\sim 2 \mathrm{Ma}$. Instead, the isotopic variations among NC meteorites were likely generated over a much shorter time interval and, as such, may record a rapidly changing composition of the disk, where each planetesimal locks the instant composition of the disk when it forms.

Constructive reviews by A. Treiman and an anonymous reviewer greatly improved this Letter and are gratefully acknowledged. We also thank E.G. Rivera-Valentín for efficient editorial handling, and the American Museum of Natural History (New York City), the Field Museum of Natural History (Chicago), the National History Museum (London), and the Smithsonian Institution (Washington, DC) for generously providing meteorite samples for this study. This project was funded by the Deutsche Forschungsgemeinschaft (DFG; German Research Foundation) Project-ID 263649064 TRR 170. This is TRR 170 pub. No. 102.

\section{Appendix}

Table A1 summarizes the $\mathrm{Mo}, \mathrm{Ti}, \mathrm{Cr}$, and $\mathrm{Ni}$ isotopic data as well as the accretion ages for the various groups of meteorites. 
Table A1

Summary of Mo, Ti, Cr, Ni, and Accretion Age Literature Data for Selected Meteorites

\begin{tabular}{|c|c|c|c|c|c|c|c|c|c|c|c|c|c|c|c|c|c|c|c|c|c|}
\hline Sample & $\varepsilon^{94} \mathrm{Mo}$ & $\begin{array}{c}95 \% \\
\mathrm{CI}\end{array}$ & $\varepsilon^{95} \mathrm{Mo}$ & $\begin{array}{c}95 \% \\
\mathrm{CI}\end{array}$ & $\Delta^{95} \mathrm{Mo}$ & $\begin{array}{c}95 \% \\
\mathrm{CI}\end{array}$ & rho & References & $\leftarrow$ Comment & $\varepsilon^{50} \mathrm{Ti}$ & $\begin{array}{c}95 \% \\
\mathrm{CI}\end{array}$ & References & $\varepsilon^{54} \mathrm{Cr}$ & $\begin{array}{c}95 \% \\
\text { CI }\end{array}$ & References & $\varepsilon^{62} \mathrm{Ni}$ & $\begin{array}{c}95 \% \\
\text { CI }\end{array}$ & References & $\begin{array}{l}\text { Accretion } \\
\text { Age }(\mathrm{Ma})^{\mathrm{a}}\end{array}$ & $2 \sigma$ & References \\
\hline \multicolumn{22}{|l|}{$\begin{array}{l}\text { Non-carbonaceous }(N C) \\
\text { meteorites }\end{array}$} \\
\hline \multicolumn{22}{|l|}{ Chondrites } \\
\hline EH & 0.47 & 0.09 & 0.18 & 0.07 & -10 & 9 & -0.61 & 1,2 & Weighted mean & -0.14 & 0.07 & 18,19 & 0.02 & 0.05 & $28,29,30$ & 0.03 & 0.03 & $51,52,53$ & 1.83 & 0.10 & 58 \\
\hline EL & 0.36 & 0.11 & 0.14 & 0.06 & -7 & 9 & -0.51 & 1,3 & $\begin{array}{l}\text { Simple mean }+ \\
\quad 95 \% \mathrm{CI}\end{array}$ & -0.28 & 0.17 & $3,19,20$ & 0.03 & 0.06 & $28,29,30$ & -0.03 & 0.07 & $3,51,52,53$ & 1.83 & 0.10 & 58 \\
\hline $\mathrm{OC}(\mathrm{H}, \mathrm{L}, \mathrm{LL})$ & 0.67 & 0.11 & 0.25 & 0.05 & -15 & 8 & -0.81 & $1,2,3,4$ & $\begin{array}{c}\text { Simple mean }+ \\
\quad 95 \% \mathrm{CI}^{\mathrm{b}}\end{array}$ & -0.66 & 0.06 & $\begin{array}{c}3,18,19,20 \\
21,22\end{array}$ & -0.40 & 0.04 & $28,29,31$ & -0.06 & 0.02 & $3,51,52,53,54$ & 2.14 & 0.10 & 58 \\
\hline $\begin{array}{l}\mathrm{RC} \\
\text { Achondrites }\end{array}$ & 0.42 & 0.10 & 0.18 & 0.05 & -7 & 8 & -0.77 & 5 & & & & & -0.11 & 0.25 & 32 & & & & 2.10 & 0.10 & 58 \\
\hline Mesosiderites & 1.04 & 0.08 & 0.46 & 0.05 & -16 & 7 & -0.69 & 5 & & -1.27 & 0.16 & 18 & -0.72 & 0.07 & 28 & & & & 0.90 & 0.30 & 58 \\
\hline Acapulcoites-Lodranites & 0.92 & 0.07 & 0.48 & 0.03 & -7 & 5 & -0.84 & 10 & & -1.48 & 0.45 & 23 & -0.62 & 0.15 & $23,32,33,34$ & & & & 1.50 & 0.50 & 63 \\
\hline Winonaites & 0.25 & 0.15 & 0.09 & 0.09 & -6 & 13 & -0.70 & 10 & & & & & & & & & & & & & \\
\hline Brachinites & 1.20 & 0.08 & 0.58 & 0.05 & -13 & 7 & -0.65 & 5,10 & Weighted mean & & & & -0.44 & 0.23 & 36 & & & & & & \\
\hline Ureilites & 0.89 & 0.09 & 0.38 & 0.04 & -15 & 7 & -0.80 & 5 & & -1.85 & 0.26 & 18 & -0.92 & 0.04 & $29,32,37,38$ & -0.07 & 0.14 & 52 & 1.00 & 0.50 & 59,62 \\
\hline Angrites & 0.75 & 0.11 & 0.39 & 0.06 & -6 & 9 & -0.72 & 5 & & -1.18 & 0.08 & 18,19 & -0.43 & 0.06 & $28,31,32,39$ & 0.01 & 0.05 & 52 & 0.50 & 0.40 & $58,64,65$ \\
\hline Aubrites & 0.48 & 0.05 & 0.25 & 0.06 & -4 & 7 & -0.44 & 5 & & -0.06 & 0.11 & 19 & -0.16 & 0.19 & 28 & 0.05 & 0.19 & 52 & 0.80 & 0.70 & 58 \\
\hline Main group pallasites & 0.85 & 0.22 & 0.38 & 0.14 & -13 & 19 & -0.68 & 7 & & -1.37 & 0.08 & 18 & -0.39 & 0.40 & 28,29 & -0.06 & 0.10 & 35 & 0.90 & 0.30 & 58 \\
\hline EET 87517 (anom. Ureilite) & 1.62 & 0.22 & 0.83 & 0.15 & -14 & 20 & -0.66 & 5 & & & & & & & & & & & & & \\
\hline PCA 82506 (anom. Ureilite) & 1.35 & 0.22 & 0.73 & 0.15 & -7 & 20 & -0.65 & 5 & & & & & & & & & & & & & \\
\hline NWA 1058 (ungr.) & 1.31 & 0.11 & 0.68 & 0.09 & -10 & 11 & -0.59 & 5 & & & & & & & & & & & & & \\
\hline NWA 6112 (ungr.) & 1.55 & 0.22 & 0.79 & 0.15 & -13 & 20 & -0.66 & 10 & & & & & & & & & & & & & \\
\hline NWA 5363/5400 (ungr.) & 0.66 & 0.22 & 0.31 & 0.15 & -8 & 20 & -0.60 & 10 & & -1.02 & 0.10 & 3 & -0.37 & 0.13 & 3 & 0.01 & 0.03 & 3 & & & \\
\hline NWA 2526 (ungr.) & 0.60 & 0.13 & 0.39 & 0.13 & 3 & 15 & -0.52 & 10 & & & & & & & & & & & & & \\
\hline NWA 725 (anom. acap.) & 1.20 & 0.24 & 0.52 & 0.16 & -20 & 21 & -0.67 & 2 & & & & & & & & & & & & & \\
\hline \multirow{2}{*}{\multicolumn{22}{|c|}{ Iron meteorites }} \\
\hline & & & & & & & & & & & & & & & & & & & & & \\
\hline IC & 0.90 & 0.06 & 0.40 & 0.03 & -14 & 5 & -0.75 & This study, 6 & Int.-der. & & & & & & & -0.07 & 0.04 & $51,55,56$ & 0.10 & 0.20 & 14 \\
\hline IIAB & 1.16 & 0.04 & 0.53 & 0.03 & -16 & 4 & -0.62 & This study & Int.-der. & & & & & & & -0.10 & 0.09 & $51,52,55$ & 0.30 & 0.20 & 14 \\
\hline IIE & 0.79 & 0.05 & 0.36 & 0.03 & -11 & 4 & -0.68 & 8 & Weighted mean & & & & -0.59 & 0.13 & 28 & & & & 1.50 & $\begin{array}{l}+0.1 /- \\
\quad \mathrm{X}\end{array}$ & 60 \\
\hline IIIAB & 1.01 & 0.04 & 0.46 & 0.04 & -15 & 5 & -0.56 & This study & Int.-der. & & & & -0.85 & 0.06 & 28 & -0.12 & 0.02 & $51,52,55$ & 0.20 & 0.20 & 14 \\
\hline IIIE & 0.96 & 0.02 & 0.46 & 0.06 & -11 & 6 & -0.20 & 6,14 & Indiv.-corr. & & & & & & & -0.07 & 0.04 & 56 & 0.30 & 0.20 & 14 \\
\hline IVA & 0.79 & 0.10 & 0.36 & 0.05 & -11 & 7 & -0.79 & 8,9 & $\begin{array}{l}\text { Simple mean }+ \\
\quad 95 \% \mathrm{CI}\end{array}$ & & & & & & & -0.07 & 0.04 & $51,52,55,56$ & 0.30 & 0.20 & 14 \\
\hline IAB sH & 0.94 & 0.27 & 0.38 & 0.13 & -18 & 21 & -0.78 & 2 & & & & & & & & & & & & & \\
\hline IAB MG-sLL & 0.04 & 0.10 & -0.07 & 0.05 & -9 & 8 & -0.77 & 9 & & & & & & & & & & & 1.40 & $\begin{array}{l}+0.1 /- \\
\quad \mathrm{X}\end{array}$ & 61 \\
\hline Gebel Kamil (ungr.) & 0.34 & 0.30 & 0.07 & 0.15 & -13 & 23 & -0.76 & 9 & & & & & & & & & & & & & \\
\hline Mont Dieu (ungr.) & 0.63 & 0.21 & 0.18 & 0.13 & -20 & 18 & -0.69 & 4 & & & & & & & & & & & & & \\
\hline \multicolumn{22}{|l|}{$\begin{array}{l}\text { Carbonaceous (CC) } \\
\text { meteorites }\end{array}$} \\
\hline \multicolumn{22}{|l|}{ Chondrites } \\
\hline CI & 0.79 & 0.41 & 0.69 & 0.23 & 22 & 34 & & 7 & & 1.85 & 0.12 & 18,19 & 1.59 & 0.06 & $\begin{array}{c}28,29,31,32, \\
40,41\end{array}$ & 0.20 & 0.14 & $51,53,54$ & 3.60 & 0.50 & 59 \\
\hline $\mathrm{CM}$ & 4.82 & 0.20 & 3.17 & 0.16 & 30 & 20 & & 7 & & 3.02 & 0.09 & $18,19,21$ & 1.10 & 0.08 & $28,29,40,42$ & 0.10 & 0.03 & $51,52,53,54$ & 3.50 & $\begin{array}{c}+0.7 /- \\
0.5\end{array}$ & 58 \\
\hline $\mathrm{CO}$ & 1.66 & 0.34 & 1.39 & 0.34 & 40 & 40 & & 11 & & 3.77 & 0.50 & 18,19 & 0.77 & 0.33 & $28,29,40$ & 0.11 & 0.04 & 51,53 & 2.70 & 0.20 & 58 \\
\hline $\mathrm{CV}$ & 0.97 & 0.19 & 0.81 & 0.05 & 23 & 12 & & 12 & & 3.47 & 0.19 & $\begin{array}{c}3,18,19,20 \\
21,24\end{array}$ & 0.86 & 0.08 & $3,28,29,40$ & 0.11 & 0.03 & $\begin{array}{c}3,51,52,53 \\
54,56\end{array}$ & 2.70 & 0.30 & 59 \\
\hline CK & 1.63 & 0.22 & 1.24 & 0.15 & 27 & 20 & & 5 & & 3.63 & 0.40 & 18,19 & 0.48 & 0.42 & 28,29 & & & & 2.60 & 0.20 & 58 \\
\hline $\mathrm{CR}$ & 3.11 & 0.15 & 2.26 & 0.04 & 41 & 10 & & 13 & & 2.63 & 0.49 & $18,19,24$ & 1.34 & 0.03 & $24,28,29$ & 0.07 & 0.08 & 51 & 3.85 & 0.15 & 59 \\
\hline $\mathrm{CH}$ & 1.79 & 0.10 & 1.29 & 0.04 & 22 & 7 & & 5 & & & & & 1.37 & 0.29 & 28 & & & & & & \\
\hline
\end{tabular}


Table A1

(Continued)

\begin{tabular}{|c|c|c|c|c|c|c|c|c|c|c|c|c|c|c|c|c|c|c|c|c|c|}
\hline \multirow[b]{2}{*}{ Sample } & \multirow[b]{2}{*}{$\varepsilon^{94} \mathrm{Mo}$} & \multicolumn{2}{|c|}{$95 \%$} & \multirow{2}{*}{$\begin{array}{c}95 \% \\
\mathrm{CI}\end{array}$} & \multirow[b]{2}{*}{$\Delta^{95} \mathrm{Mo}$} & \multicolumn{2}{|c|}{$95 \%$} & \multirow[b]{2}{*}{ References } & \multirow[b]{2}{*}{$\leftarrow$ Comment } & \multirow[b]{2}{*}{$\varepsilon^{50} \mathrm{Ti}$} & \multirow{2}{*}{$\begin{array}{c}95 \% \\
\mathrm{CI}\end{array}$} & \multirow[b]{2}{*}{ References } & \multirow[b]{2}{*}{$\varepsilon^{54} \mathrm{Cr}$} & \multicolumn{2}{|l|}{$95 \%$} & \multirow[b]{2}{*}{$\varepsilon^{62} \mathrm{Ni}$} & \multicolumn{2}{|l|}{$95 \%$} & \multirow{2}{*}{$\begin{array}{l}\text { Accretion } \\
\text { Age }(\mathrm{Ma})^{\mathrm{a}}\end{array}$} & \multirow[b]{2}{*}{$2 \sigma$} & \multirow[b]{2}{*}{ Reference: } \\
\hline & & $\mathrm{CI}$ & $\varepsilon^{95} \mathrm{Mo}$ & & & $\mathrm{CI}$ & rho & & & & & & & $\mathrm{CI}$ & References & & $\mathrm{CI}$ & References & & & \\
\hline $\begin{array}{l}\mathrm{CB} \\
\text { Iron meteorites }\end{array}$ & 1.26 & 0.04 & 0.99 & 0.04 & 24 & 5 & & 5 & & 2.04 & 0.07 & 18 & 1.20 & 0.09 & $28,40,43,44$ & & & & & & \\
\hline IIC & 2.22 & 0.09 & 1.54 & 0.06 & 22 & 8 & & 14 & & & & & & & & 0.16 & 0.08 & 56 & 0.90 & $\begin{array}{c}+0.4 /- \\
0.2\end{array}$ & 14 \\
\hline IID & 1.18 & 0.07 & 1.01 & 0.03 & 31 & 5 & & $\begin{array}{c}\text { This study, } \\
6,14\end{array}$ & Int.-der. & & & & & & & 0.19 & 0.08 & 56 & 0.90 & $\begin{array}{c}+0.4 /- \\
0.2\end{array}$ & 14 \\
\hline IIF & 1.11 & 0.13 & 0.94 & 0.08 & 28 & 11 & & 14 & & & & & & & & 0.09 & 0.04 & 56 & 0.90 & $\begin{array}{c}+0.4 /- \\
0.2\end{array}$ & 14 \\
\hline IIIF & 1.20 & 0.11 & 0.99 & 0.04 & 27 & 8 & & 14 & & & & & & & & 0.12 & 0.10 & 56 & 1.00 & 0.20 & 14 \\
\hline IVB & 1.54 & 0.10 & 1.16 & 0.05 & 24 & 8 & & 4 & & & & & & & & 0.07 & 0.04 & $51,52,55$ & 1.00 & 0.20 & 14 \\
\hline \multicolumn{22}{|c|}{ Inclusion-like (IC) reservoir } \\
\hline CAI & 1.23 & 0.19 & 1.97 & 0.08 & 124 & 14 & & $7,15,16$ & $\begin{array}{c}\text { Simple mean }+ \\
\quad 95 \% \mathrm{CI}\end{array}$ & 8.33 & 0.47 & $25,26,27$ & 5.97 & 0.52 & $\begin{array}{c}28,45,46,47,48 \\
49,50\end{array}$ & 0.55 & 0.24 & 57 & & & \\
\hline
\end{tabular}

Notes. The e-notation is the parts per $10^{4}$ deviation relative to the terrestrial bracketing solution standard. The uncertainties represent the 2 standard deviations $\left(2\right.$ s.d.) for samples with $N \leqslant 3$ and Student- $t 95 \%$ confidence intervals, i.e., $t_{0.95}, N-1 \times$ s.d.) $/ \sqrt{ } N$, for $N \geqslant 4$. ${ }^{a}$ After the formation of Ca-Al-rich inclusions (CAI).

${ }^{\mathrm{b}}$ Excluding Richardton metal and Saint-Séverin.

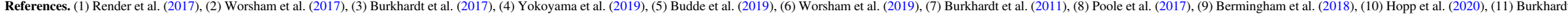

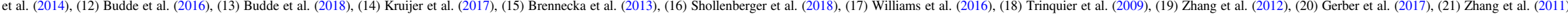

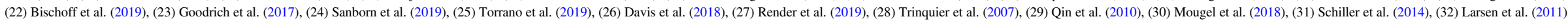

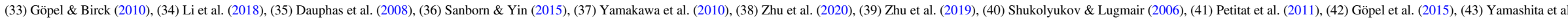

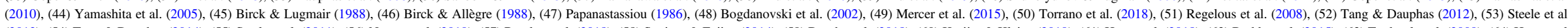

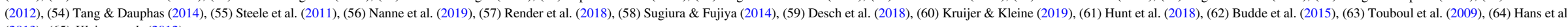
(2013), (65) Kleine et al. (2012). 


\section{ORCID iDs}

Fridolin Spitzer (1) https://orcid.org/0000-0002-6114-0854 Christoph Burkhardt (1) https://orcid.org/0000-0002-6952-5783 Gerrit Budde (1) https://orcid.org/0000-0003-0762-779X Thomas S. Kruijer (i) https://orcid.org/0000-0003-0974-4324 Alessandro Morbidelli iib https://orcid.org/0000-0001-8476-7687 Thorsten Kleine 누 https://orcid.org/0000-0003-4657-5961

\section{References}

Bermingham, K. R., Worsham, E. A., \& Walker, R. J. 2018, E\&PSL, 487, 221 Birck, J. L., \& Allègre, C. J. 1988, Natur, 331, 579

Birck, J. L., \& Lugmair, G. W. 1988, E\&PSL, 90, 131

Bischoff, A., Barrat, J. A., Berndt, J., et al. 2019, ChEG, 79, 125525

Blackburn, T., Alexander, C. M. O. D., Carlson, R., \& Elkins-Tanton, L. T. 2017, GeCoA, 200, 201

Bogdanovski, O., Papanastassiou, D. A., \& Wasserburg, G. J. 2002, LPI, 33, 1802

Brasser, R., \& Mojzsis, S. J. 2020, NatAs, 4, 492

Brennecka, G. A., Borg, L. E., \& Wadhwa, M. 2013, PNAS, 110, 17241

Brennecka, G. A., Burkhardt, C., Kruijer, T. S., \& Kleine, T. 2017, LPI, 48, 1619

Budde, G., Burkhardt, C., Brennecka, G. A., et al. 2016, E\&PSL, 454, 293

Budde, G., Burkhardt, C., \& Kleine, T. 2019, NatAs, 3, 736

Budde, G., Kruijer, T. S., Fischer-Gödde, M., Irving, A. J., \& Kleine, T. 2015, E\&PSL, 430, 316

Budde, G., Kruijer, T. S., \& Kleine, T. 2018, GeCoA, 222, 284

Burkhardt, C., Dauphas, N., Hans, U., Bourdon, B., \& Kleine, T. 2019, GeCoA, 261, 145

Burkhardt, C., Dauphas, N., Tang, H., et al. 2017, M\&PS, 52, 807

Burkhardt, C., Hin, R. C., Kleine, T., \& Bourdon, B. 2014, E\&PSL, 391, 201

Burkhardt, C., Kleine, T., Oberli, F., et al. 2011, E\&PSL, 312, 390

Carrera, D., Gorti, U., Johansen, A., \& Davies, M. B. 2017, ApJ, 839, 16

Dauphas, N., Cook, D. L., Sacarabany, A., et al. 2008, ApJ, 686, 560

Davis, A. M., Zhang, J., Greber, N. D., et al. 2018, GeCoA, 221, 275

Desch, S. J., Kalyaan, A., \& Alexander, C. M. O. 2018, ApJS, 238, 11

Elkins-Tanton, L. T., Weiss, B. P., \& Zuber, M. T. 2011, E\&PSL, 305, 1

Gerber, S., Burkhardt, C., Budde, G., Metzler, K., \& Kleine, T. 2017, ApJL, 841, L17

Gerbig, K., Lenz, C. T., \& Klahr, H. 2019, A\&A, 629, A116

Goodrich, C. A., Kita, N. T., Yin, Q. Z., et al. 2017, GeCoA, 203, 381

Göpel, C., \& Birck, J.-L. 2010, GeCoA, 74, A348

Göpel, C., Birck, J. L., Galy, A., Barrat, J. A., \& Zanda, B. 2015, GeCoA, 156, 1

Hans, U., Kleine, T., \& Bourdon, B. 2013, E\&PSL, 374, 204

Haugbølle, T., Weber, P., Wielandt, D. P., et al. 2019, AJ, 158, 55

Hellmann, J. L., Kruijer, T. S., van Orman, J. A., Metzler, K., \& Kleine, T. 2019, GeCoA, 258, 290

Hevey, P. J., \& Sanders, I. S. 2006, M\&PS, 41, 95

Hopp, T., Budde, G., \& Kleine, T. 2020, E\&PSL, 534, 116065

Hunt, A. C., Cook, D. L., Lichtenberg, T., et al. 2018, E\&PSL, 482, 490

Jacquet, E., Pignatale, F. C., Chaussidon, M., \& Charnoz, S. 2019, ApJ, 884,32

Kleine, T., Budde, G., Burkhardt, C., et al. 2020, SSRv, 216, 55

Kleine, T., Hans, U., Irving, A. J., \& Bourdon, B. 2012, GeCoA, 84, 186

Kruijer, T. S., Burkhardt, C., Budde, G., \& Kleine, T. 2017, PNAS, 114, 6712

Kruijer, T. S., Fischer-Gödde, M., Kleine, T., et al. 2013, E\&PSL, 361, 162

Kruijer, T. S., \& Kleine, T. 2019, GeCoA, 262, 92

Kruijer, T. S., Kleine, T., \& Borg, L. E. 2020, NatAs, 4, 32

Kruijer, T. S., Touboul, M., Fischer-Gödde, M., et al. 2014, Sci, 344, 1150

Larsen, K. K., Trinquier, A., Paton, C., et al. 2011, ApJL, 735, L37

Li, S., Yin, Q. Z., Bao, H., et al. 2018, GeCoA, 242, 82

Lock, S. J., Stewart, S. T., Carter, P. J., et al. 2019, LPI, 50, 1783

Ludwig, K. R. 2008, Berkeley Geochronl. Cent. Spec. Publ., 4, 1

Mercer, C. M., Souders, A. K., Romaniello, S. J., et al. 2015, LPI, 1832, 2920

Morbidelli, A., Bitsch, B., Crida, A., et al. 2016, Icar, 267, 368

Morbidelli, A., Libourel, G., Palme, H., Jacobson, S. A., \& Rubie, D. C. 2020 , E\&PSL, 538, 116220
Mougel, B., Moynier, F., \& Göpel, C. 2018, E\&PSL, 481, 1

Mughabghab, S. F. 2003, Thermal Neutron Capture Cross Sections, Resonance Integrals and g-Factors, INDC(NDS)-440, IAEA,Vienna

Nanne, J. A. M., Nimmo, F., Cuzzi, J. N., \& Kleine, T. 2019, E\&PSL, 511, 44

Palme, H., Lodders, K., \& Jones, A. 2014, in Planets, Asteroids, Comets and The Solar System, Vol. 2 of Treatise on Geochemistry, ed. A. M. Davis (2nd ed.; Amsterdam: Elsevier), 15

Papanastassiou, D. A. 1986, ApJL, 308, L27

Pape, J., Mezger, K., Bouvier, A. S., \& Baumgartner, L. P. 2019, GeCoA, 244, 416

Petitat, M., Birck, J. L., Luu, T. H., \& Gounelle, M. 2011, ApJ, 736, 23

Poole, G. M., Rehkämper, M., Coles, B. J., Goldberg, T., \& Smith, C. L. 2017 , E\&PSL, 473, 215

Qin, L., Alexander, C. M. O. D., Carlson, R. W., Horan, M. F., \& Yokoyama, T. 2010, GeCoA, 74, 1122

Qin, L., Dauphas, N., Horan, M. F., Leya, I., \& Carlson, R. W. 2015, GeCoA, 153, 91

Regelous, M., Elliott, T., \& Coath, C. D. 2008, E\&PSL, 272, 330

Render, J., Brennecka, G. A., Wang, S.-J., Wasylenki, L. E., \& Kleine, T. 2018, ApJ, 862, 26

Render, J., Ebert, S., Burkhardt, C., Kleine, T., \& Brennecka, G. A. 2019 , GeCoA, 254, 40

Render, J., Fischer-Gödde, M., Burkhardt, C., \& Kleine, T. 2017, Geochemical Perspect. Lett., 3, 170

Sanborn, M. E., Wimpenny, J., Williams, C. D., et al. 2019, GeCoA, 245, 577

Sanborn, M. E., \& Yin, Q.-Z. 2015, LPI, 46, 2241

Schiller, M., Bizzarro, M., \& Fernandes, V. A. 2018, Natur, 555, 501

Schiller, M., Bizzarro, M., \& Siebert, J. 2020, SciA, 6, eaay7604

Schiller, M., van Kooten, E., Holst, J. C., Olsen, M. B., \& Bizzarro, M. 2014, J. Anal. At. Spectrom., 29, 1406

Shollenberger, Q. R., Borg, L. E., Render, J., et al. 2018, GeCoA, 228, 62

Shukolyukov, A., \& Lugmair, G. W. 2006, E\&PSL, 250, 200

Steele, R. C. J., Coath, C. D., Regelous, M., Russell, S., \& Elliott, T. 2012, ApJ, 758, 59

Steele, R. C. J., Elliott, T., Coath, C. D., \& Regelous, M. 2011, GeCoA, 75,7906

Stephan, T., Trappitsch, R., Hoppe, P., et al. 2019, ApJ, 877, 101

Stewart, S. T., Carter, P. J., Davies, E. J., et al. 2019, LPI, 50, 1251

Sugiura, N., \& Fujiya, W. 2014, M\&PS, 49, 772

Tang, H., \& Dauphas, N. 2012, E\&PSL, 359, 248

Tang, H., \& Dauphas, N. 2014, E\&PSL, 390, 264

Torrano, Z. A., Brennecka, G. A., Williams, C. D., et al. 2019, GeCoA, 263, 13

Torrano, Z. A., Rai, V. K., \& Wadhwa, M. 2018, LPI, 49, 2405

Touboul, M., Kleine, T., Bourdon, B., et al. 2009, E\&PSL, 284, 168

Trinquier, A., Birck, J., \& Allegre, C. J. 2007, ApJ, 655, 1179

Trinquier, A., Elliott, T., Ulfbeck, D., et al. 2009, Sci, 324, 374

Warren, P. H. 2011, E\&PSL, 311, 93

Weber, P., Benítez-Llambay, P., Gressel, O., Krapp, L., \& Pessah, M. E. 2018, ApJ, 854, 153

Wendt, I., \& Carl, C. 1991, Chem. Geol. Isot. Geosci. Sect., 86, 275

Williams, C. D., Janney, P. E., Hines, R. R., \& Wadhwa, M. 2016, ChGeo, 436, 1

Wittig, N., Humayun, M., Brandon, A. D., Huang, S., \& Leya, I. 2013, E\&PSL, 361, 152

Worsham, E. A., Bermingham, K. R., \& Walker, R. J. 2017, E\&PSL, 467, 157

Worsham, E. A., Burkhardt, C., Budde, G., et al. 2019, E\&PSL, 521, 103

Yamakawa, A., Yamashita, K., Makishima, A., \& Nakamura, E. 2010, ApJ, 720,150

Yamashita, K., Maruyama, S., Yamakawa, A., \& Nakamura, E. 2010, ApJ, 723,20

Yamashita, K., Ueda, T., Najamura, N., Kita, N., \& Heaman, L. M. 2005, in NIPR Symp. 29, Antarctic Meteorites (Tokyo: NIPR), 100

Yang, L., \& Ciesla, F. J. 2012, M\&PS, 47, 99

Yokoyama, T., Nagai, Y., Fukai, R., \& Hirata, T. 2019, ApJ, 883, 62

Zhang, J., Dauphas, N., Davis, A. M., Leya, I., \& Fedkin, A. 2012, NatGe, 5,251

Zhang, J., Dauphas, N., Davis, A. M., \& Pourmand, A. 2011, J. Anal. At. Spectrom., 26, 2197

Zhu, K., Moynier, F., Schiller, M., et al. 2020, ApJ, 888, 126

Zhu, K., Moynier, F., Wielandt, D., et al. 2019, ApJL, 877, L13 